\title{
Descriptive Study: Congenital Malformations in Pediatric Patients of a Public Maternity Hospital of the City of Manaus, Amazonas
}

Cleiton Fantin, Denise Corrêa Benzaquem, Marcelo Lasmar Santos, Carlos Augusto da Silva Araújo Júnior, Lilian Barroso Carvalho, Natanael Martins Gomes, Larissa Nascimento Souza and Gabriela Bentes Sousa

Laboratory of Cytogenetics, State University of Amazonas, Manaus, Amazonas, Brazil

\begin{abstract}
The Pan American Health Organization (PAHO) defines congenital malformation as any functional or structural anomaly in the development of the fetus, due to factors originating before birth, whether genetic, environmental or unknown. The aim of the present study was to identify the frequency of malformations, the type of congenital malformations and to correlate this with risk factors in live-born infants, using SLB data. The data were collected through consultation of the medical records of live-born infants of the Balbina Mestrinho Maternity Hospital, 15,621 live births were reported, of which 248 (1.58\%) presented congenital malformations. There was a higher prevalence of malformations among live-born males (49.7\%), with Apgar $\geq 7$ at the first and fifth minute, gestational age ranging from 37-41 weeks, with $46 \%$ being born with appropriate weight between 3,000-4,000 g. The association of two or more defects was observed in $38.7 \%$ of the total cases and isolated anomalies in $67.3 \%$, with predominance of alterations of the digestive system (26.3\%), followed by malformations of the musculoskeletal system (21.2\%), nervous system (20.2\%) and cleft lip/cleft palate $(9.1 \%)$. The results presented here may guide strategic actions to improve care for families of people with congenital malformations.
\end{abstract}

Key words: Congenital abnormalities, epidemiological inquiry, prevalence, newborn.

\section{Introduction}

The term congenital defect refers to any type of anomaly, being anatomical, functional or metabolic, caused by a Mendelian type hereditary transmission mechanism, or caused by recent gene mutation, chromosomal alteration or by physical, chemical and infectious damage, which affects the developing fetus or embryo. Its detection may occur at birth or develop throughout childhood development [1-3].

The cause of congenital defects in most cases has multiple factors, among them, maternal characteristics such as age, with greater age in the mother leading to increased chances of a significant change in the fetus [4]. Genetic factors, heredity, also play a role, as in the case of cleft lip and palate patients, who in the majority

Corresponding author: Cleiton Fantin, Ph.D., professor, research fields: genetics and cytogenetics. of cases had a relative or ancestor with the same condition [5] as well as socioeconomic conditions [6] Since 1999, Brazil has included in the completion of the Statement of Live Birth (SLB) information specifically for the reporting of congenital malformations and chromosomal anomalies, in field 34, in a succinct way.

Pediatric and neonatal conditions related to congenital malformations present a challenge for health professionals working in this area, since they are often under diagnosed conditions, mainly due to the lack of availability of diagnostic tests as well as the shortage of professionals specialized in the cytogenetic diagnosis of children with any clinical alteration that corroborates a genetic disorder.

Identifying the health and illness profiles of a population is a key factor for the implementation of public policies aimed at prevention, promotion and 
treatment of diseases in a community. Based on the above, congenital anomalies can be considered part of the current public health problem and of great relevance, more specifically in the state of Amazonas, where there is a scarcity of health data, since research carried out in this area is still insipient. Given these considerations, the study aimed to describe the profile of live-born infants with clinical and/or laboratory diagnosis of congenital malformation born in the city of Manaus from January 2010 to December 2014.

\section{Materials and Methods}

A retrospective and descriptive study was carried out from Jan. 2010 to Dec. 2014 and included all the patients seen in the maternity hospital that presented congenital malformations. Secondary data were obtained from 163 medical records filed at the Medical Archiving Service (Serviço de Arquivamento Médico SAME) of the Balbina Mestrinho Maternity Hospital. For the data collection a structured questionnaire based on information in the Statement of Live Birth (SLB) was used, as were medical forms completed by physicians (Obstetricians, Neonatologists, and Intensive care staff) and, when present, information contained in the diagnostic and imaging tests, such as Ultrasound and X-rays. Cases of newborns who did not present clinical and/or laboratory diagnoses of congenital malformation were excluded from the study, as were charts that were incorrectly completed or contained inconsistent information, those not found by the research team and those physically damaged (wet, stained, etc.). The variables of interest selected for analysis were maternal characteristics (maternal age, history of family congenital malformation and abortions), gestation and delivery data (gestational age, type of delivery, number of prenatal consultations performed) newborn data (sex, weight, Apgar score at the first and fifth minute) and requests for karyotype examination. The data obtained were first tabulated in a database, using the Microsoft Office Excel 2013 program, and subsequently analyzed using the SPSS
16.0 statistical package, with tests carried out to obtain the mean, median and standard deviation. The study was approved by the Research Ethics Committee of the State University of Amazonas, under authorization No. 048/2012, following all legal and ethical aspects of research involving human subjects, according to Resolution 466/12 of the National Health Council.

\section{Results}

Of the total cohort of live-births (LBs) between 2010 and 2014 at the Balbina Mestrinho Maternity Hospital ( $N=15,621), 248(1.58 \%)$ presented a report of some type of congenital malformation and 15,373 (98.42\%) had this field ignored or blank. The majority of the diagnoses of malformation, made soon after the birth, were clinical (87.7\%), with the karyotype examination being requested in only $4.9 \%$ of the cases. Of the total of 248 cases, only $163(65.7 \%)$ were located in the SAME of the Balbina Mestrinho Maternity Hospital, representing an absence of $45.2 \%$ of the total medical records.

Among the records found $(n=163)$, field 34 had not been completed in 4 , which corresponded to $2.5 \%$ of the total. However, the case of congenital malformation was observed by checking the chart and verifying the description from the complete physical examination of the newborn in the delivery room.

In relation to the profile of those born with congenital malformations, of the absolute total, $49.7 \%$ ( $n=81)$ were male; the Apgar score at the first and fifth minute was greater than $7(73.6 \%$ and $82.2 \%$, respectively); the predominant gestational age was 37 to 41 weeks $(74.8 \%)$; and $46 \%(n=75)$ presented appropriate weight between 3,000-4,000 g (Table 1).

The younger mothers of LBs were between 20 and 24 years of age $(28.2 \%)$ and the older mothers, in the over 35 years age group, the age at which the possibility of birth defects increases, totaled 27 (16.6\%); 113 of the total number of mothers did not present a history of abortion and 73 reported no cases of congenital malformation in the family, however, this 
information was unavailable for 90 cases; 143 mothers underwent prenatal care, of whom 64 attended 4 to 6 consultations, 105 had cesarean section deliveries, which corresponds to $64.4 \%$ (Table 2).

The association of two or more defects was observed in $38.7 \%$ of the total cases, and single anomalies in
$67.3 \%$, with predominance of alterations of the digestive system (26.3\%), followed by malformations of the musculoskeletal system $(21.2 \%)$ of the nervous system (20.2\%) and cleft lip/cleft palate (9.1\%) (Table 3). The cases of associated congenital malformation are listed in Table 4.

Table 1 Profile of the newborn infants with congenital malformations in the Balbina Mestrinho Maternity Hospital, from 2010 to 2014, including sex, Apgar 1st minute, Apgar 5th minute, gestational age and birth weight. Manaus, AM, Brazil $(n=$ 163).

\begin{tabular}{|c|c|c|}
\hline Variable & No. & $\%$ \\
\hline \multicolumn{3}{|l|}{ Sex } \\
\hline Male & 81 & 49.7 \\
\hline Female & 72 & 44.2 \\
\hline Ignored & 4 & 2.5 \\
\hline Undetermined & 1 & 0.6 \\
\hline No information & 5 & 3.1 \\
\hline Total & 163 & 100 \\
\hline \multicolumn{3}{|l|}{ Apgar 1st minute } \\
\hline$<7$ & 35 & 21.5 \\
\hline$>7$ & 120 & 73.6 \\
\hline No information & 8 & 4.9 \\
\hline Total & 163 & 100 \\
\hline \multicolumn{3}{|l|}{ Apgar 5th minute } \\
\hline$<7$ & 21 & 12.9 \\
\hline$>7$ & 134 & 82.2 \\
\hline No information & 8 & 4.9 \\
\hline Total & 163 & 100 \\
\hline \multicolumn{3}{|c|}{ Gestational age (weeks) } \\
\hline$<37$ & 38 & 23.3 \\
\hline $37-41$ & 122 & 74.8 \\
\hline$>42$ & 2 & 1.2 \\
\hline Total & 163 & 0.6 \\
\hline \multicolumn{3}{|l|}{ Birth weight* } \\
\hline Low weight & 30 & 18.4 \\
\hline Insufficient weight & 46 & 28.2 \\
\hline Appropriate weight & 75 & 46 \\
\hline Fetal macrosomia & 6 & 3.7 \\
\hline No information & 6 & 3.7 \\
\hline Total & 163 & 100 \\
\hline
\end{tabular}

\footnotetext{
* Low weight (<2,500 g); Insufficient weight (2,500-3,000 g); Appropriate weight (3,000-4,000 g); Fetal macrosomia (> 4,000 g).
} 
Table 2 Maternal data: Age range, case of family malformation, abortion, type of delivery, prenatal care and number of consultations, referring to cases of congenital malformations that occurred in the Balbina Mestrinho Maternity Hospital, in the period 2010-2014. Manaus, AM, Brazil $(n=162)$.

\begin{tabular}{|c|c|c|}
\hline Variables & No. & $\%$ \\
\hline \multicolumn{3}{|l|}{ Age group (years) } \\
\hline$\leq 15$ & 4 & 2.5 \\
\hline $15-19$ & 31 & 19 \\
\hline $20-24$ & 46 & 28.2 \\
\hline $25-29$ & 32 & 19.6 \\
\hline $30-34$ & 21 & 12.9 \\
\hline$\geq 35$ & 27 & 16.6 \\
\hline No information & 2 & 1.2 \\
\hline Total & 163 & 100 \\
\hline \multicolumn{3}{|c|}{ Case of malformation in the family? } \\
\hline No & 73 & 44.8 \\
\hline No information & 90 & 55.2 \\
\hline Total & 163 & 100 \\
\hline \multicolumn{3}{|c|}{ History of abortion? } \\
\hline Yes & 45 & 27.6 \\
\hline No & 113 & 69.3 \\
\hline No information & 5 & 3.1 \\
\hline Total & 163 & 100 \\
\hline \multicolumn{3}{|l|}{ Type of birth } \\
\hline Vaginal & 57 & 35 \\
\hline Cesarean section & 105 & 64.4 \\
\hline No information & 1 & 0.6 \\
\hline Total & 163 & 100 \\
\hline \multicolumn{3}{|c|}{ Performed prenatal care? } \\
\hline Yes & 143 & 87.7 \\
\hline No & 17 & 10.4 \\
\hline No information & 3 & 1.8 \\
\hline Total & 163 & 100 \\
\hline \multicolumn{3}{|c|}{ No. of consultations } \\
\hline None & 13 & 8 \\
\hline $1-3$ & 23 & 14.1 \\
\hline $4-6$ & 64 & 39.3 \\
\hline 7 and more & 54 & 33.1 \\
\hline No information & 7 & 4.3 \\
\hline No information & 2 & 1.2 \\
\hline Total & 163 & 100 \\
\hline
\end{tabular}


Table 3 Single congenital malformations occurring in the period from 2010 to 2014, in the Balbina Mestrinho Maternity Hospital, classified according to the ICD 10. Manaus, AM, Brazil $(n=163)$.

\begin{tabular}{lll}
\hline Type of Malformation & F & $\%$ \\
\hline Digestive system & 26 & 26.3 \\
Musculoskeletal system & 21 & 21.2 \\
Nervous system & 20 & 20.2 \\
Cleft lip/cleft palate & 9 & 9.1 \\
Eye, ear, face and neck & 8 & 8.1 \\
Genital Organs & 6 & 6.1 \\
Other malformations & 6 & 6.1 \\
Chromosomal abnormalities, not classified elsewhere & 2 & 2 \\
\hline
\end{tabular}

Table 4 Multiple congenital malformations occurring in the period from 2010 to 2014, in the Balbina Mestrinho Maternity Hospital, classified according to the ICD 10. Manaus, AM, Brazil $(n=163)$.

\begin{tabular}{|c|c|c|c|}
\hline Types of multiple malformations & $f$ & $\%$ & Valid \% \\
\hline Absence of pinna, micrognathism, misshapen fingers, absence of scrotal sac & 1 & 1.8 & 2.1 \\
\hline PAD, VSD, ASD, syndromic facies & 1 & 1.8 & 2.1 \\
\hline Cardiomegaly, clubfoot & 1 & 1.8 & 2.1 \\
\hline Cardiopathy, cryptorchidism & 1 & 1.8 & 2.1 \\
\hline Encephalocele, micropenis & 1 & 1.8 & 2.1 \\
\hline Facial proboscis, holoprosencephaly, Patau syndrome? & 1 & 1.8 & 2.1 \\
\hline Down syndrome-like facies, moderate ostium secundum ASD, PAD & 1 & 1.8 & 2.1 \\
\hline Syndromic facies, absence of nasal bone, auricular pedicle, permeable foramen ovale & 1 & 1.8 & 2.1 \\
\hline Syndromic facies, absence of second pododactyl & 1 & 1.8 & 2.1 \\
\hline Syndromic Facies, VSD, ASD, bilateral congenital chylothorax & 1 & 1.8 & 2.1 \\
\hline Facies syndromic, bilateral hydrothorax & 1 & 1.8 & 2.1 \\
\hline $\begin{array}{l}\text { Syndromic facies, low implantation of ears, enlarged and short neck, musculoskeletal } \\
\text { malformation }\end{array}$ & 1 & 1.8 & 2.1 \\
\hline Syndromic facies, micrognathia, left atrial appendage & 1 & 1.8 & 2.1 \\
\hline Syndromic facies, bilateral congenital clubfoot & 1 & 1.8 & 2.1 \\
\hline Syndromic facies, pectus carinatum & 1 & 1.8 & 2.1 \\
\hline Complete cleft palate, cardiopathy & 1 & 1.8 & 2.1 \\
\hline Gastroschisis, malformation in lower limbs & 1 & 1.8 & 2.1 \\
\hline Umbilical hernia, absence of ear canal, hypospadia, omphalocele, cleft palate & 1 & 1.8 & 2.1 \\
\hline Hydrocephalus, absence of eyeball, nostrils and ear and left upper limb, gastroschisis & 1 & 1.8 & 2.1 \\
\hline Hydrocephalus, absence of nasal bone, absence of right ear canal & 1 & 1.8 & 2.1 \\
\hline Hydrocephalus, absence of nasal bone, absence of eyeball & 1 & 1.8 & 2.1 \\
\hline Hydrocephalus, cleft palate, cleft lip & 1 & 1.8 & 2.1 \\
\hline $\begin{array}{l}\text { Hydrocephalus, microphthalmia, agenesis of nasal bones, cleft palate, micropenis, } \\
\text { cryptorchidism }\end{array}$ & 1 & 1.8 & 2.1 \\
\hline Hydrocephalus, low implantation of ears & 1 & 1.8 & 2.1 \\
\hline Hydrops, multiple malformations & 1 & 1.8 & 2.1 \\
\hline $\begin{array}{l}\text { Hypertelorism, single palmar fold, macroglossia, micropenis, PAD and permeable } \\
\text { foramen ovale }\end{array}$ & 1 & 1.8 & 2.1 \\
\hline Lower limb and pelvis hypoplasia, hypospadia, ASD with hemodynamic repercussion & 1 & 1.8 & 2.1 \\
\hline Pulmonary immaturity, cardiopulmonary insufficiency & 1 & 1.8 & 2.1 \\
\hline Low implantation of ears, macroglossia, down syndrome-like facies & 1 & 1.8 & 2.1 \\
\hline Cleft palate, cleft lip, eye malformation & 1 & 1.8 & 2.1 \\
\hline Cleft lip, cleft palate, preauricular papule & 1 & 1.8 & 2.1 \\
\hline Cleft lip, cleft palate, gastroschisis & 1 & 1.8 & 2.1 \\
\hline Macrocephaly, myelomeningocele, clubfoot & 1 & 1.8 & 2.1 \\
\hline Malformation in the oropharynx and upper limbs & 1 & 1.8 & 2.1 \\
\hline
\end{tabular}


(Table 4 continued)

\begin{tabular}{|c|c|c|c|}
\hline Types of multiple malformations & $f$ & $\%$ & Valid \% \\
\hline Multiple malformations, clubfoot, syndromic facies, malformations in the abdomen & 1 & 1.8 & 2.1 \\
\hline Multiple malformations, indefinite sex & 1 & 1.8 & 2.1 \\
\hline Megacystis, pulmonary hypoplasia, giant hydronephrosis & 1 & 1.8 & 2.1 \\
\hline Microcephaly, myelomeningocele, cleft lip & 1 & 1.8 & 2.1 \\
\hline Myelomeningocele, clubfoot & 1 & 1.8 & 2.1 \\
\hline Myelomeningocele, bilateral congenital clubfoot, permeable foramen ovale, macrocephaly & 1 & 1.8 & 2.1 \\
\hline Myelomeningocele, clubfoot, hydrocephalus & 1 & 1.8 & 2.1 \\
\hline Multiple & 1 & 1.8 & 2.1 \\
\hline Multiple malformations, hydrocephalus & 1 & 1.8 & 2.1 \\
\hline Omphalocele, gastroschisis & 1 & 1.8 & 2.1 \\
\hline Omphalocele, hydrocephalus, renal malformation, absence of urethral orifice and clitoris & 1 & 1.8 & 2.1 \\
\hline Omphalocele, clubfoot & 1 & 1.8 & 2.1 \\
\hline Clubfoot, hydrocephalus, micrognathia, umbilical stump with anomalous implantation & 1 & 1.8 & 2.1 \\
\hline CHARGE syndrome (ASD, VSD, PAD), bilateral choanal atresia, ocular malformation & 1 & 1.8 & 2.1 \\
\hline Total & 48 & 87.3 & 100.0 \\
\hline Missing & 7 & 12.7 & \\
\hline Total & 55 & 100 & \\
\hline
\end{tabular}

\section{Discussion}

In the present study, among the live births in the maternity hospital mentioned, the occurrence of congenital anomalies from 2010 to 2014 was 248 cases (1.58\%). Studies indicate that the general incidence of congenital malformations in Latin America is no different to other regions of the world. Studies show that approximately $5.0 \%$ of live births present some developmental anomaly, which may be totally or partially caused by hereditary factors [7]. This statistic was confirmed by Horovitz et al. [8] in a study in which the authors report that in Brazil the occurrence of congenital anomalies is similar to that found in other regions of the world, with, generally, between $2 \%$ and $5 \%$ of the Brazilian live-born infants having some congenital defect. According to information obtained from the Live Births Information System (SINASC) published by the Department of Informatics of the Brazilian National Health System (DATASUS), and the Brazilian Institute of Geography and Statistics (IBGE), in Amazonas, in the year 2013 there was a total of $1.54 \%$ (510) of the population with congenital defects and in the city of Manaus, $0.41 \%$ (325) born with congenital defects in the same year [9].
The relatively low number of congenital malformations found in the results (1.58\%) compared to the worldwide and national means is due in part to the inadequate completion of the SLB and the absence of some medical records. The delineation of the epidemiological profile of congenital diseases in Brazil is based on the primary source for statistical studies, in this case the SLB, for which adequate completion is of fundamental importance for the prevention of underreporting. In order for the results to reflect the observed reality, the records must be reliable and trustworthy [10]. According to other studies, inadequate completion and storage of the SLB is discouraging. One study conducted in Brazil evaluated the quality of information contained in the SLB through SINASC, the study showed that the information presented demonstrated clarity for most of the data provided, however, this was not observed with regard to field 34 [11]. Studies indicate that the completion is heterogeneous, performed by physicians, nursing assistants or nurses. There is no place to report the function of the declarant and it is also not obligatory for this to be a physician, a fact supported by the booklet produced by the ministry of health.

Another factor that contributed to these results was 
the loss of medical records. Of a total of 248 cases that were to be included in the study, only 163 were found, evidencing a certain lack of official documents, inadequate storage and other unforeseen circumstances, such as flooding of the Balbina Mestrinho Maternity Hospital archive, which made data collection difficult.

Regarding the profile of the newborn infants with congenital malformations, the prevalence of male newborns was observed, the same was observed in studies performed in several regions of the country [10, 12-16]. In the present study, those born with congenital malformations had an Apgar score greater than 7 at one and five minutes, which reflects good vitality at birth. In the study conducted by Rodrigues et al. [15] the same result was found. However, Nhoncanse et al.[13] analyzing births with congenital malformations in the city of São Carlos-SP, observed that the majority of them, when compared to the control group, had Apgar index at the 1 st minute of $0-3(46.8 \%)$ and at the 5 th minute of 8-10 (34\%). It should be noted that in the cases observed here, the Apgar score of less than 7 was described from the physical examination of those born with associated malformations, which consequently led to a series of, often severe and fatal, clinical repercussions.

In relation to gestational age, the newborn infants were classified as full-term, that is, with gestational age between 37 and 41 weeks, with this result having been described by other authors [10, 14, 15]. Considering the birth weight, Reis et al. [10] and Rodrigues et al. [15] highlighted that the majority of live births with malformations present appropriate weight, ranging from 3,000 to 4,000 grams, with this being the case in the patients of the present study.

Contrary to expectations, in the present study, advanced maternal age did not constitute a risk factor for the incidence of congenital malformation, since the age group above 35 years, considered at risk, presented a total of 27 cases, which represents less than $20 \%$. There was a significant prevalence of congenital malformation among women aged 20 to 29 years, representing $47.8 \%$ of the cases analyzed. Studies report the prevalence of congenital defects in live births where mothers were aged between 20 and 34 years, ages compatible with those observed in the present study $[13,15,17]$.

Prenatal care was performed in $87.7 \%$ of the cases, which is a very high percentage. The highest number of malformations was observed among women who attended 4 to 6 prenatal care consultations, with these numbers being lower than that recommended by the Ministry of Health, which indicates a minimum number of seven consultations to monitor a low-risk pregnancy [18]. Factors such as education and schooling are of paramount importance for ensuring quality prenatal care. Parents with higher levels of education and access to information have a strong influence on the quality of life of their children, guaranteeing their survival until the age of five years, feeding them adequately and with them presenting good development [19]. Although a diagnosis of malformation is independent of these factors, it is essential to emphasize that in some cases, a low level of education is closely related to the socioeconomic profile, which may lead to nutritional deficiencies that may favor the occurrence of fetal malformations [10, 20].

The most prevalent type of delivery was cesarean section delivery, with surgical intervention occurring in $64.4 \%$ of the pregnancies. There was a correlation between cesarean section delivery and the presence of newborns with congenital malformation. This positive association is due to the fact that the mothers received the diagnosis of malformation during the intrauterine phase and the procedure was a medical decision. Operative delivery is indicated in high-risk pregnancies, as a safety measure for the mother and the baby, as surgical precision reduces maternal and infant mortality considerably [10, 21].

Regarding the types of congenital malformations found in this study, $100(67.3 \%)$ of the LBs had single anomalies and (63) $38.7 \%$ of the cases were 
represented by situations in which two or more minor and major defects coexisted (Tables 3 and 4). In a study evaluating the prevalence of congenital malformations in the city of Rio de Janeiro, Reis et al. [10] reported that the predominant malformations were related to the osteo-muscular and articular system (39.8\%), followed by other malformations (22.8\%); central nervous system (13.8\%); genitourinary system (11.5\%); craniofacial malformations (5.6\%); circulatory system (3.1\%) and digestive system (3.0\%). The authors stated that the predominance of musculoskeletal malformations can be related to the easy diagnosis and, automatically, to the premature, antenatal and immediate postnatal diagnosis, since they are easily recognized in the physical examination, due to them being microsomal malformations.

The results of this study reflect, in a general way, how the SLB is completed and especially how this document, which is extremely important for epidemiological investigations, has been neglected in some maternity hospitals. It should be noted that estimating the prevalence of congenital malformations using data from the SLB is significantly more reliable when there are few fields not completed in the document, in this study the field corresponding to congenital anomalies was not completed in only 4 statements, accounting for $2.5 \%$ of the total. Furthermore, the large number of SLBs that were missing, deteriorating or had parts erased should be taken into consideration, as these were not included in this study, leading to a substantial loss of the sample. Accordingly, the accuracy in completing the SLB is extremely important, since it is the direct source of notification for evaluating the need to adopt new prevention strategies.

\section{Conclusion}

The present study reinforces the need for technical training and greater attention in completing the SLB data. This would help provide reliable data on the prevalence of newborns with congenital abnormalities, as well as the identification of possible causes, contributing to the planning of maternal care through improving the quality of the access of women and newborn infants to the specialized services. Therefore, further studies may form a base for knowledge on the occurrence of congenital malformation and optimization of the completion of the SLB.

\section{Acknowledgements}

Data collection and interpretation were performed by: Marcelo Lasmar Santos, Carlos Augusto da Silva Araújo Junior, Lilian Barroso Carvalho, Natanael Martins Gomes, Larissa Nascimento Souza and Gabriela Bentes Sousa, as well as part of the writing. The writing of the article and critical review of the intellectual content were carried out by Denise Corrêa Benzaquem. Final approval of the version to be published was made by Cleiton Fantin.

\section{Conflicts of Interest}

The authors report no conflicts of interest regarding the present manuscript.

\section{References}

[1] Castilla, E. E., Lopez-Camelo, J. S., Paz, J. E., and Orioli, I. M. 1996. Prevención primaria de los defectos congénitos. 1st ed. Publishing company FIOCRUZ, Rio de Janeiro, p. 147.

[2] Horovitz, D. D. G., Llerena Junior, J. C., and Mattos, R. A. 2005. "Attention to the Congenital Defects in Brazil: Current Panorama." Cad Saúde Pública 4: 1055-64.

[3] Pereira, R. J. S., Abreu, L. C. de, Valenti, V. E., Albuquerque, W. D. M., Pereira, S. C., Araújo, R., et al. 2008. "Frequency of Congenital Malformations of the Extremities in Newborns." Rev Bras Crescimento Desenvolv Hum 2: 155-62.

[4] Souza, J. M. P., Buchalla, C. M., and Laurenti, R. 1987. "Study of Perinatal Morbidity and Mortality in Maternity Hospitals." Rev Saúde Públ 1: 5-12.

[5] Loffredo, L. C. M., Souza, J. M. P., Yunes, J., Freitas, J. A. S., and Spiri, W. C. 1994. "Lip-Palate Clefts: A Case Control Study." Rev Saúde Públ 3: 213-7.

[6] Basso, O., Olsen, J., and Christensen, K. 1999. "Recurrence Risk of Congenital Anomalies-The Impact of Paternal, Social and Environmental Factors: A Population Based Study in Denmark." Am J Epidemiol 6: 
598-604.

[7] Penchaszadeh, V. B., Christianson, A. L., Giugliani, R., Boulyjenkov, V., and Katz, M. 1999. "Services for the Prevention and Management of Genetic Disorders and Birth Defects in Developing Countries." Community Genet 2: 196-201.

[8] Horovitz, D. D. G., Cardoso, M. H. C. A., Llerena Jr, J. C., and Mattos, R. A. 2006. "Attention to Birth Defects in Brazil: Characteristics of Care and Proposals for the Formulation of Public Policies in Clinical Genetics." Cad Saúde Públ 12: 2599-608.

[9] Ministry of Health. 2001. Department of Informatics of SUS DATASUS. Health and Mortality Information. Brasília: Ministry of Health.

[10] Reis, A. T., Santos, R. S., and Mendes, T. A. R. 2011. "Prevalence of Congenital Malformations in the Municipality of Rio do Janeiro, Brazil, between 2000 and 2006." Rev de Enferm UERJ 3: 364-8.

[11] Nhoncanse, G. C., and Melo, D. G. 2012. "Reliability of the Declaration of Live Birth as a Source of Information about Birth Defects in the Municipality of São Carlos, São Paulo, Brazil." Science and Collective Health 4: 955-63.

[12] Guerra, F. A. R., Llerena Jr, J. C., Gama, S. G. N., Cunha, C. B., and Theme Filha, M. M. 2008. "Congenital Defects in the City of Rio de Janeiro, Brazil: An Assessment through SINASC (2000-2004).” Cad Saúde Públ (Rio J) 1: $140-9$.

[13] Nhoncanse, G. C., Germano, C. M. R., de Avó, L. R. S., and Melo, D. G. 2014. "Maternal and Perinatal Aspects of Congenital Defects: A Case-Control Study." Rev Paul Pediatr 1: 24-31.

[14] Fontoura, F. C., and Cardoso, M. V. L. M. L. 2014. "Association of Congenital Malformations with Neonatal and Maternal Variables in Neonatal Units in a Brazilian Northeastern City." Texto Contexto Enferm 4: 907-14.

[15] Rodrigues, L. S., Lima, R. H. S., Costa, L. C., and Batista, R. F. L. 2014. "Characteristics of Children Born with Congenital Malformations in the Municipality of São Luís, Maranhão, 2002-2011." Epidemiol Serv Saúde 2: 295-304.

[16] Mendes, C. Q. S., Avena, M. J., Mandetta, M. A., and Balieiro, M. M. F. G. 2015. "Prevalence of Live Births with Congenital Anomalies in the City of São Paulo." Rev Soc Bras Enferm Ped 1: 7-12.

[17] Castro, M. L. S., Cunha, C. J., Moreira, P. B., Fernández, R. R., Garcias, G. L., and Martino-Roth, M. G. 2006. "Frequency of Multiple Malformations in Newborns in the City of Pelotas, Rio Grande do Sul, Brazil, and Associated Demographic Factors.” Cad Saúde Públ 5:1009-15.

[18] Ministry of Health. 2000. "Secretariat of Health Policies. Technical Area of Women's Health. Maternal Emergencies and Emergencies: A Guide for Diagnosis and Conduct in Situations of Risk of Maternal Death.” Brasília: Ministry of Health.

[19] United Nations Children's Fund (UNICEF). Situação Mundial da Infância. Resumo Executivo. 2015. [Citado em 2015 mar 15]. Disponível em: http://www.unicef.org/publications/files/SOWC_2015_S ummary_Portuguese_Web.pdf.

[20] Brito, V. R. S., Sousa, F. S., Gadelha, F. H., Souto, R. Q., Rego, A. R. F., and França, I. S. X. 2010. "Congenital Malformations and Maternal Risk Factors in Campina Grande-Paraíba." Rev Rene 2: 27-36.

[21] Victora, C. G., and Barros, F. C. 2001. "Infant Mortality due to Perinatal Causes in Brazil: Trends, Regional Patterns and Possible Intervention." Med J 1: 33-42. 